\title{
Erratum to: L-strip Feed Circular Disk Dual Resonator Patches Antenna for Wireless Communication
}

\author{
Anurag Mishra • J. A. Ansari • Nagendra Prasad Yadav • \\ Prabhakar Singh • Babau R. Vishvakarma
}

Published online: 6 August 2013

(C) Springer Science+Business Media New York 2013

\section{Erratum to: Wireless Pers Commun DOI 10.1007/s11277-013-1014-2}

The authors of "L-strip Feed Circular Disk Dual Resonator Patches Antenna for Wireless Communication" should be shown as Anurag Mishra, J. A. Ansari, Nagendra Prasad Yadav, Prabhakar Singh, and Babau R. Vishvakarma.

The online version of the original article can be found under doi:10.1007/s11277-013-1014-2.

A. Mishra $(\varangle)$. J. A. Ansari · P. Singh

Department of Electronics and Communication, University of Allahabad, Allahabad 211003, India e-mail: mishraanurag31@gmail.com

J. A. Ansari

e-mail: jaansari@rediffmail.com

P. Singh

e-mail: prabhakarsingh3@gmail.com

N. P. Yadav · B. R. Vishvakarma

JSS Academy of Technical Education, Noida 201301, India

e-mail: nagendra_yadav0919@rediffmail.com

B. R. Vishvakarma

Varanasi, India

e-mail: brvish@bhu.ac.in 